\title{
PERSPECTIVE
}

\section{Responsibility for Eco-systems and problems of social traps and dilemmas}

\begin{abstract}
Hans Lenk
Abstract: Responsibility is a function of power, impact and knowledge. The more strategically central one's position is in terms of power, influence and knowledge, the higher his or her responsibility would be. This is an idea which can be worked out in more detail by using distributive models of graph theory and predistribution assignments of rights and duties according to different levels.
\end{abstract}

Keywords: Eco-systems, social traps and dilemmas

\section{Ecological sins economical and/or moral}

Our natural environment with its resources of landscapes, forests etc.. is not only to be considered as an asset highly appreciated for aesthetic, healthy and touristic aims and offers therefore unreplaceable opportunities for personal and group or family pleasures and nature experiences or sporting work-outs. Yet, natural resources always were and still are and will remain a source of great economic value for profitable exploitation. Think of the lumber and timber tradition and business. Under different aspects, "nature" is a treasure to capitalize on. Only recently, economists started trying to evaluate, if not theoretically commercialize, "nature" as a "capital" under divers economical terms. ${ }^{[1]}$ And as such it is vied for, exploited under the standards of competition and markets etc.. And "nature" is almost everywhere in danger by now. Erosion, pollution, and other forms of industrial damages and degeneration of nature really looms large as everybody knows by now - and many already "suffer" from such ecological deteriorisation - even in so-called "natural paradise" regions.

Ecological damages in the industrialized nations if they can be assessed in monetary value at all amount(ed) to about 3-5\% of the Gross National Product (GNP). Yet, these damages are thus far not comprised in the GNP. What are the compensatory or defensive expenditures (amounting to about $10 \%$ of some countries'

Received: January 25, 2019; Accepted: February 6, 2019; Published: February 8, 2019

* Correspondence to: Hans Lenk, Institut fr Philosophie, Karlsruhe Institute of Technology, Karlsruhe, Germany; Email: hans.lenk@kit.edu

Citation:Hans Lenk. Responsibility for Eco-systems and problems of social traps and dilemmas, Resour Environ Econ, 2019, 1(1): 1-9.

Copyright: (c) 2019 Hans Lenk. This is an open access article distributed under the terms of the Creative Commons Attribution License, which permits unrestricted use, distribution, and reproduction in any medium, provided the original author and source are credited. budgets), which are indeed an increasing factor for the GNP, although their sole function is damage compensation?

To begin with, ecological damages and, for that matter, irreversible ones, can usually not simply be attributed to a single (individual) producer or responsible person. For instance, already as early as 1989 the external costs of environmental damages only concerning the field of motor traffic were assessed by the director of the Federal Agency for Environmental Protection, Wicker, at the level of approximately 25 billion US \$. (By the way, the total assessment of man-made damages to the ecology for the very same relatively small country amounted to 103,5 billion German Marks.) But this also does not refer to individual damage attributions, with regard to somebody who is or many who are personally responsible although car traffic is usually mainly considered an individual affair in the first place.

There is no such thing as solely economical, technological action on a purely individual basis, each technoeconomical action is embedded in - and therefore implies -social and socio-cultural contexts, is unavoidably a social action, and this applies to the same extent to the consequences of such actions. Usually every action has consequences for the environment, although not every consequence necessarily results from one single action itself.

The division of labor in corporations and large-scale projects on the one hand and the coordination of actions through markets on the other hand, but especially unwanted and yet unseen combinations of unfavourable factors, which are inclined to result in catastrophes, or even subliminal negligence or carelessness as with the so-called "normal catastrophes" analysed by Perrow will complicate the attribution of (unwanted) consequences 
of actions, and the attribution of responsibility in all its kinds. The individualistic concepts of ethics and philosophy, technology and economy do not suffice to tackle these problems, they are obviously not adequate, since they usually focus almost exclusively on individual actions and not on interactive, collective and corporate forms of actions or structural and systematic contexts. Thus far ethical approaches have indeed been too much oriented toward individual persons, they have not paid enough attention to social aspect; the problems are not yet adequately adjusted to socio-ethics and social philosophy. This has been mentioned quite a while ago. ${ }^{[2]}$

It is true, so far the problems of complex constellations of causes and the problems of responsibility have been discussed only in a rather generalized way in philosophical literature, while jurisprudence is considering them in a much more detailed manner and has indeed come up with some very interesting approaches for solutions which are of interest for philosophy as well.

In addition, generally speaking one should distinguish the external responsibility for the organization and corporate action from the internal problem of responsibility distribution. The same is true with respect to institutional moral versus personal moral responsibility, although certainly an indirect connection obtains to be traced and analysed case by case which however does not amount to a general definitional reduction of corporate responsibility to solely individualistic terms or factors.

Corporations can act intentionally and non-reducibly (in a "secondary" sense, on a higher supra-individualistic i.e. participatory, fictional, social level, which is symbolically and semantically structured and interpreted; their actions nevertheless are "real" in their effects, for example in their social effects). Such a corporate responsibility, which is not equivalent with the direct personal responsibility that only individuals have to bear, may apply not only to businesses but also to the state and corporations like associations of technicians and scientists or other professions. So far the traditional aprioristic linking of attributing moral responsibility to natural persons only with the concepts of responsibility defined but in individualistic terms seemed to set up insuperable barriers to the endeavour of attributing moral responsibility to corporations and institutions. Does this really and necessarily have to turn out like that? Have we failed in our efforts with respect to the development of exclusively individualistic models? Should we not rather develop a model with hierarchic levels that differentiates among the responsibilities on the various levels and takes them into account? This is a subject being under vital and differentiating discussion in the USA these days.

Rendering or making corporations responsible may represent a first step towards attributing responsibility for corporate actions; the problem of distributing responsibility (in corporations) has to be approached then in a further step. The latter has to be treated with a differentiation among the various types of responsibility as mentioned. However, division of labour will complicate the perception and acceptance of responsibility as well as the attribution of respective consequences of a technology to an individual's marginal part within the totality. Thus, the abilities to perceive and differentiate responsibilities need to be improved as well.

We must differentiate between the problem of coresponsibility, i.e. the distribution of responsibility to (contributing) individuals in corporate respectively noncorporate action, and the problem, whether or not corporations as such can be attributed a specific responsibility at all. The former topic consists of the question whether and how the various kinds of collective responsibility can be referred or reduced to individuals. (The moral responsibility of individuals should not - as we saw - be replaced or diluted by collective responsibility - individuals can be co-responsible.) This does not mean that collective responsibility is apt to be totally resolved or diluted into individual (moral) responsibilities in each case. Not every responsibility can be completely resolved into the respective individuals' singular responsibilities. Collective responsibilities may exist, that are not reducible to individual responsibilities "without remainder", although they are at least connected with individual responsibilities and should be of relevance for these. The analysis of the intriguing connections is an important task of further pragmatic moral philosophy which indeed presupposes the elaboration of rather differentiated concepts of types and levels without which the interconnections could not be traced, identified and analyzed.

In economics and social science scholars speak of the externalities problem, side-effects, social costs, social traps, the Prisoners' Dilemma, and the public goods problem. In the classical situation of the Prisoners' Dilemma two prisoners (A, B) are indicted for armed robbery. Both are offered to be chief witness and to come free without penalty. Both of them can only be convicted because of illegal possession of weapons. Therefore, if both remain silent, both have to expect only a rather minor punishment (of, say, one year in prison), but a much higher punishment (ten years), if one is convicted (punishment for the chief witness would be zero). Therefore, confessing seems to be preferable as the dominant strategy. If one of the two confesses, it is also profitable for the other one to confess, because then he would receive eight instead of ten years imprisonment. The amount 
of punishment is therefore not only dependent on one's own strategy, but also on that of the co-prisoner. Now the dilemma of the social trap consists in the fact that it turns out to be irrational for $\mathrm{A}$ as well as B in their own interest to confess (dominant strategy). But if both of them would act rationally, i.e. both would confess, they would incur a higher punishment (eight years each in prison) than if both would keep silent (only one year each), i.e. if they would act cooperatively. Individual rationality therefore leads to collective irrationality and self-damage.

We might easily conceive of a positive variant of the PD which we would like to call the Naturalists' Dilemma or, in more general terms, the Enjoyers' Dilemma or Environmentalist's (ED) with respect to scarce resources. Imagine the only lake in a nature-reserve (e.g. in a US National Forest) which is to be enjoyed and partially utilized by anglers and waterskiers at the same time. For the sake of argument the lake should not be that large that both could enjoy their sport at or on the lake without interfering with one another. If both the anglers and the waterskiers would use the lake unrestrictedly they would not to be able to enjoy their sport at or on the lake at all. The waterskier would mingle with the anglers' lines expelling and deterring the fish from the range of the anglers' reach. Thus, they apparently have to come to an agreement with one another in order to be able both to enjoy a nature reserve. They have to arrange for restrictions by, e.g. segmenting space or time. They might allot part of the lake to the waterskiers and the other to the anglers or they might for instance allow to waterski only every second day. Other possibilities of restrictions are conceivable. However, any restriction and segmentation whatsoever would decrease a full-scale enjoyment of both parties. Therefore, the dilemma which arises does not develop from the bargaining of negative sanctions as in the classical PD, but it is a dilemma of the fullscale enjoyment with respect to scarce nature reserve. In this variant, not sanctions of the object of the potential agreement, but the possibility and degree of positively enjoying the natural source or resource are at stake. It is largely the same idea as Hardin (1968) had in mind with the overgrazing of the Sahel zone. The most important difference from the PD is that in ED situations tiered possibilities or levels of opportunities of utilisation do occur (by contradistinction to the yes-or-no-strategies involved in the PD model) which admit of variations with regard to degrees or intensity of utilisation or even partially dispensing with them. Here, the pay-offs may - within limits - be at will determined or chosen by steps.

It might be as difficult to reach an agreement in this sort of Enjoyers' Dilemma as in the classical PD. How- ever, it is not just a change in signs in the respective utility and evaluation functions, but different points of equilibria might occur.

Generally speaking, the positive variant of the Enjoyers' Dilemma seems to be of considerable interest besides the classical and static PD restricted to a bargaining of negative sanctions. The Enjoyers' or Naturalists' Dilemma seems not only to apply to the use of common land or nature reserves, but also to privately owned and exploited land if it is embedded in an endangered ecological environment, because the groundwater level as well as clean air or drought or polluted air, erosion and depletion would not stop at a conventional borderline, but affect the whole local, regional or even continental ecology. It certainly is a pressing problem, e.g. with regard to nature resources and recreation facilities in the vicinity of cities and larger metropolitan or 'metroplex' areas of dense population in particular.

The central point with respect to the problem of the distribution of responsibility is the question concerning the normative and descriptive "distributability" (susceptibility for distribution) in terms of the theory of action and the possibility of adequately reducing the collective responsibility to individual actors in relation to the form of collective actions and causations. Thus, the respective form of a collective action is of determining value and figures as a criterion for the distinction of various attributions of responsibility. Another important point is that the distribution of responsibility is dependent on the kind of responsibility: If one differentiates between a legal liability for compensation and moral responsibility, a distribution is (more) easily attainable with the first kind, while it might be not (so) easy with moral responsibility. In particular, the negative formulations of a responsibility for prevention of damages and the preservation of states of well-being etc.. are relevant for the distribution of responsibilities - as is the responsibility to prevent omissions, which is more easily accessible for a regulation of responsibility. One should also differentiate between the sufficient and the necessary conditions of a consequence or damage in relation to several involved persons' failures to act. So, the individual failure to act is causally sufficient for the occurrence of the consequence or damage, if non-omission of the act prevents this occurrence.

Thus, there exists an ethical obligation for humans to take care that especially humankind - as well as other natural kinds dependent on the human power for intervention - does not get extinguished. It is true that individual beings, which have not yet been conceived, have no individual moral or legal right to be born, and one cannot impose an individual obligation on particular human 
couples to procreate, but it seems to be a sensible extrapolation from the constitutional rights of humankind, which are else often only constructed as rights of repulse and protection, to develop a collective responsibility of today's living humans that they must not let their species be extinguished or destroyed. Humans have not only the - negative - responsibility to leave behind wholesome conditions of environment and life for future generations, which means they should not totally exploit nonregenerative raw-materials and should refrain from lethal poisoning, depletion and destruction of the environment. They collectively also have an obligation and responsibility to actively prevent this from happening and to work for a future existence of humankind in life conditions worthy of human beings. This is at least a moral demand which originates in the integrity and continued existence of humankind, which are considered the highest desirable values by various ethical systems. Even a version of Kant's (AA IV, 341) formal Categorical Imperative refers to the actual content of the "principle of humankind and of any reasoning nature" as things in themselves.

Judged morally, then, future generations' relative rights or quasi-rights to existence do exist, even though no singular existence of a non-conceived individual can be sued for on a moral or legal basis. Thus, certain general human and moral obligations transcend those which are individualistically and juristically concretized. Moral value commitments are more comprehensive and determining than moral or legal individual responsibilities. Morality is more than a singular individual responsibility or obligation.

\section{Social traps, Prisoners' Dilemma situations etc. as pertaining to land, and environment}

In economics and social science many scholars speak of social traps, the externalities problem, side-effects, social costs, the Prisoners' Dilemma, and the public goods problem. I would like to illustrate the problem first by using the problem structure of the so-called "Tragedy of the Commons". ${ }^{[2]}$ This constellation can be understood as a prototype of a social trap. The central question here will turn out to be: Who would bear the responsibility for an action result and for the respective consequences which nobody had wanted or intended beforehand?

According to Hardin every owner of stock in the Sahel zone has an individual and perfectly legitimate interest in utilizing and exploiting the common grassland, the so-called "commons", which is indeed a collective good. This individual interest is characterized by striving to own as many animals as possible, because the greater one's own stock, the higher is one's social status. All the owners and society in general, however, have a common interest, a real commonality, namely to avoid overgrazing of the "commons". This constellation of individual and common interests would lead to the following dilemma: Because nobody has sufficient individual interest to avoid extensive exploitation of the "commons", but just strives for one's own good. Hence, everybody will utilize these "commons" as extensively as possible. Therefore overgrazing of the Sahel "commons" would be the necessary result and consequently in the last analysis the very satisfaction of the individual interests would be barred or ruined, respectively. Hardin thinks it necessary to have social, i.e. non-individual mechanisms of control, in order to avoid such a dilemma. A controlling mechanism would have to be socially enforced. Hardin emphasized that such "tragedies of the commons" would undermine or at least relativize the well-known traditional theorem of "the invisible hand" after Adam Smith. ${ }^{[3]}$ According to Hardin the rational maximizing of each individual interest need not (and in the "tragic" dilemma situation cannot), via dynamic market processes lead to an optimum result and wealth for all. On the contrary, it must lead to depletion, erosion and pollution etc.., of the common land. A similar problem with respect to arable land use also leads to depletion, erosion, even devastation of arable land in large parts of Africa: the only few remaining trees and shrubs are necessarily used and/or consumed to satisfy pressing survival interests of individual families. This consumption leads to further expansion ${ }^{[2]}$ of the desert and to an additional deterioration of sustenance and survival conditions of the whole population etc. (With respect to stock and the above-mentioned traditional conflict between the individual owners' interests and social needs even the boring of additional wells might even aggravate or escalate the conflict constellation and accelerate the ecological problems. This might be a well-known unintended side-effect of political and economic development programs.)

A similar effect is the clearing and making arable of tropical rain forests on basically poor soil which might lead to local and regional erosion and depletion of the ecosystem and to a continental or even global change of the climate (cf. the global carbon dioxide and methane problem and the impending glass-house effect of overheating the atmosphere and the whole climate).

According to Hardin the problem of environmental pollution turns out to be of analogical or equivalent structure. The commons, a public good in this case, however, is not diminishing or decreasing in size, but instead a negative quality is added, namely through the deposit- 
ing of refuse of many kinds. Again, it is profitable, i.e. cheaper, for the individual agent to do away with garbage on public soil, e.g., to deposit chemical refuse in the Rhine as was traditional before 1900. (A clearance commission was installed only in 1908. As a consequence of these public measures external social costs would result.)

Negative external effects which would amount to a burden for the general societies. They can only be avoided, mitigated or re-directed if the taxpayer or everybody pays in money or is suffering in terms of health disadvantages, deterioration of quality of life or of aesthetic values of ecosystems and the landscape. So-called "externalities" (impacts from outside of the traditional economic model) would result from the actions of producers and consumers whenever these agree on actions which would be disadvantageous for the environment (think of the example of the one-way bottles). Therefore, there is also a responsibility of consumers, e.g., co-responsibility with respect to the protection of the environment. On different levels of a scaling phenomenon all members of a society would bear a certain responsibility for an acceptable or good and healthy state of their respective society. ${ }^{[4]}$

Generally speaking the same structure is to be found with many problems of social constellations which can be dubbed social trap constellations. It would be profitable for individuals to infringe social rules and norms as long as (almost) all other members are abiding by them. A similar structure is to be found in the so-called FreeRider Problem and the "assurance problem" ${ }^{[5]}$ with respect to providing and maintaining collective and public goods. Both cases lead to so-called "social traps". The dilemma of environmental protection on a voluntary basis is an intriguing example of this constellation. The free-rider problem is "A barrier to successful collective action or to the production of a public good that arises because all or some individuals attempt to take a free ride on the contribution of others. Non-contributors (would) reason as follows: Either enough others will contribute to achieve the good or they will not, regardless of whether I contribute or not; but if the good is achieved, I will benefit from it even if I don't contribute. Consequently, since contributing is a cost, I should not contribute". ${ }^{[5]}$

The provision and maintenance of a collective good is according to Olson (1968) primarily dependent on the magnitude of group membership: The greater a group of participating individuals, the less the chance and opportunity turn out to be for providing and maintaining such a good and the greater is the necessity of compulsion, law enforcement, sanctions etc. . with respect to usage and distribution of collective goods. Whereas community norms or a morale would still seem satisfactory for reaching a common goal in small groups, this does not apply to large groups. (Buchanan called this phenomenon "the large number dilemma". ${ }^{[5]}$ )

The structural problems of social and individual actions, of public goods, and of the commons and social order can easily be illustrated by using the wellknown game theoretical model of the so-called Prisoners' Dilemma (PD). A detailed analysis of the PD structure shows that strategic actions of competing selfinterested rational agents lead to a result which turns out to be an unintended social consequence putting all participants on a worse level than a cooperative strategy of abiding by social rules would have obtained. PDconstellations cannot be solved on a pure individualistic level.

The above-mentioned dilemmas are also examples of rationality traps: the individually rational action strategy leads to collective social irrationality undermining the first one. Under certain conditions, individual rationality can be self-destructive.

The second problem of distributing responsibility does not result from collective corporate action by itself, but only if many act under strategic (competitive) conditions, if negative external, synergistic and/or cumulative effects occur. Indeed, "strategic conditions" means that the final result is dependent on the (relatively independent) acting of many individual agents. Synergistic and cumulative effects would only result, if different components have a joint and mutually escalating impact; the individual components might by themselves be (relatively) harmless, i.e. remain under a certain threshoId-value, but yet result in the deterioration or even loss of a highly valued common good (think of the example of the continental European forest "dying" from pollution by acid rain and erosion).

\section{Naturalists' or Enjoyers' Dilemmas}

Earlier (1998, 439f), I dubbed the distribution dilemma regarding the using or enjoying a nature resource or eco-system by different users (e.g. fishermen and anglers, hobby sailors, rowers, swimmers, naturalists etc.. taking advantage of a lake) "the Naturalists' Dilemma". By contradistinction to the PD, this situation can be pragmatically tackled and the problems solved by dividing and distributing spaces and/or times, certainly e.g., by mutual agreement.

Indeed, there are also positive variants of Naturalists' Dilemmas:

"We might easily conceive of a positive variant of the PD which I would like to call the Naturalists' Dilemma or, in more general terms, the Enjoyers' Dilemma or 
Environmentalist's Dilemma with respect to scarce resources. Imagine the only lake in a nature-reserve (e.g. in a US National Forest) which is to be enjoyed and partially utilized by anglers and water-skiers at the same time. For the sake of argument the lake should not be that large that both could enjoy their sport at or on the lake without interfering with one another. If both the anglers and the water-skiers would use the lake unrestrictedly they would not to be able to enjoy their sport at or on the lake at all. The water-skier would mingle with the anglers' lines expelling and deterring the fish from the range of the anglers' reach. Thus, they apparently have to come to an agreement with one another in order to be able both to enjoy a nature reserve. They have to arrange for restrictions by, e.g. segmenting space or time. They might allot part of the lake to the water-skiers and the other to the anglers or they might for instance allow to water-ski only every second day. Other possibilities of restrictions are conceivable. However, any restriction and segmentation whatsoever would decrease a full-scale enjoyment of both parties. Therefore, the dilemma which arises does not develop from the bargaining of negative sanctions as in the classical PD, but it is a dilemma of the encompassing enjoyment with respect to scarce nature reserves. In this variant, not sanctions of the object of the potential agreement, but the possibility and degree of positively enjoying the natural source or resource are at stake. It is largely the same idea as Hardin (1968) had in mind with the overgrazing of the Sahel zone. The most important difference from the classical PD is that in Enjoyers's Dilemma situations tiered possibilities or levels of opportunities and/or utilisation do occur (by contradistinction to the yes-or-no-strategies involved in the PD model) which admit of variations with regard to degrees or intensity of utilisation or even partially dispensing with them. Here, the pay-offs might be determined within limits - at will or chosen by steps.

Generally speaking, the mentioned positive variant of a Naturalists' Dilemma, the Enjoyers' Dilemma, seems to be of considerable interest besides the classical and rather static PD restricted to a bargaining of negative sanctions. The Enjoyers' or Naturalists' Dilemma seems not only to apply to the use of common land or nature reserves, but also to privately owned and exploited land if it is embedded in an endangered ecological environment, because the groundwater level as well as clean air or polluted air, drought and/or soil erosion and depletion would not stop at a conventional borderline, but affect the whole local, regional or even continental ecology.- In the future, more than ever we have to take this problem seriously into account - particularly with regard to nature resources and recreation facilities in the vicinity of cities and larger metropolitan areas of dense population.”[6-10]

\section{Extended and distributed responsibility and eco-liability}

The distribution or, rather, distributability problem of responsibility consists in the fact that side-effects cannot be attributed to a single originator and that they usually are or even could not be foreseen or predicted. We have two partial problems here: First the question of participatory responsibility with respect to cumulative and synergistic harmful effects and second the question how to responsibly deal with unforeseen or even unpredictable facts or side-effects. The first problem can be called the problem of distributing responsibility under strategic conditions. For instance, is the legal principle of attributing "causality" and responsibility valid in Japan indeed satisfactory? It is in force since the case of the Minamata disease according to which the statistically assessed contribution to the common harm by relevant polluters in the vicinity is so to speak automatically ascertained by law, as the pertaining causality. The burden of proof here lies so to speak on the side of the potential originator as the hypostatized polluter, who has to prove the harmlessness of his emissions. This reversal of the burden of proof of the respective attribution seems to be at least a controllable and operational measure to allow for evaluations and distributions wherever environmental damages are in question. In these detriments usually land, water and air use or misuse are combined. They can at least be forestalled or diminished in a controllable way by assigning sanctions. In that respect the Japanese legal principle of attributing causality might foster environmental protection. But there are methodological and legal as well as moral problems connected with such a regulation. First of all, adjacency and the guessing of causality can never be a proof of a causal origin.

In addition, the problem is how to attribute and distribute the responsibility in the cases of synergistic and cumulative damages, particularly those with belowthreshold contributions of individual agents. Another problem is how to distinguish between a descriptive assessment of causal origination and the normative attribution of responsibility, between causal responsibility and liability after Hart (1968). How could one possibly distinguish between the causal impact, the descriptive responsibility, i.e. the descriptive attribution of responsibility, and the respective normative attribution of responsibility for contributions on the one side - and on the other hand the amount of which subliminal detrimental impact (and how much of it) is individually ineffective, below the threshold of harmfulness? And how is one to 
distribute this kind of responsibility in general? Would it not be meaningful to postulate a normative collective responsibility of all pertinent corporations within the respective region in the sense of a joint liability? This would, however, mean a liability of all relevant corporations for the total damages. The impaired parties could sue for damages, claim in court for compensation and/or indemnification from any presumably participating corporation. Does this make sense, if connected with an overall generalization? This regulation, however, would have the advantage of dispensing with the proof of damage in respect of each singular damaging or aggrieving party. This kind of regulation would, in some way independent of individual case argumentation, interpret all non-collective agents as quasi one corporative agent being liable in total. The internal distribution and compensation within this quasi-group of corporate agents would then be a problem of mutual bargaining amongst all aggrieving parties.

Notwithstanding these arguments another kind of total liability with respect to product safety and hazards in terms of environmental damages of public goods should be established. It should be noted that there is a European Community agreement as of 1985 with regard to product liability laws. Causal originators of damages would then/now be liable in the sense of a strict liability in tort, whether or not they are really guilty in terms of intent or only negligent. Causal origination would already ascertain descriptive causal action responsibility and with respect to the damage of a good to be protected also normative responsibility for the respective action and its consequences. This form of liability would hopefully be deterrent enough to prevent infringements. If, however, damages would nevertheless occur, it would at least not be necessary to prove fault or guiltiness as a presupposition of any claim for compensation.

Are human beings because of their immense power of technical encroachment and feasibility beyond any beforehand imagination and control now collectively responsible for much more, so to speak, than they could possibly foresee and literally (intentionally) be normatively responsible for? Should they not take over responsibility for unforeseen or even unforeseeable side-effects of their actions with respect to technological and scientific big science projects? But how could they possibly do that? There is no way of really morally being held responsible for something one does not know or even could not know. In the sense of causal responsibility (descriptive origination) can one be held responsible in some sense, if an unintended damage occurs? The question however is, whether one could be held here responsible in a normative-moral sense too. The so-called "principle of causation" if interpreted in a moral and legal sense, would - at least in tendency - adequately engender normative responsibility also. One would have to answer for, to make good for and to be liable for consequences in the sense of being liable to pay compensation etc.. The range and power of action seems to have multiplied or grown to such a degree that anticipation cannot follow quickly enough or pursue all the complex ramifications of impacts, consequences and side-effects. This is true notably in our ever-extending complexity of societal and interdisciplinary interactions, be they direct or indirect. That seems to be an intriguing dilemma of responsibility in our systems technological age ${ }^{[11]}$ impregnated by complex systems interactions and dynamic changes easily transgressing linear thinking and traditional causal disciplinary knowledge. In principle this also pertains to eco-systems and their respective land bases.

\section{Distribution Problems of Responsibilities}

"The central point with respect to the problem of the distribution of responsibility is the question concerning the normative and descriptive "distributability" in terms of a theory of action and the possibility of adequately reducing the collective responsibility to individual agents in relation to the form of collective actions and causations. Thus, the respective form of a collective action is of determining value and figures as a criterion for the distinction of various attributions of responsibility (see above, chap. 10). Another important point is that the distribution of responsibility is dependent on the kind of responsibility: If one differentiates between a legal liability for compensation and moral responsibility, a distribution is (more) easily attainable and combined with the first kind, while it might be not (so) easy with moral responsibility. In particular, the negative formulations of a responsibility for prevention of damages and the preservation of states of well-being etc.. are relevant for the distribution of responsibilities - as is the responsibility to prevent omissions, which is more easily accessible for a regulation of responsibility. One should also differentiate between the sufficient and the necessary conditions of a consequence or damage in relation to several involved persons' failures to act. So, the individual failure to act is causally sufficient for the occurrence of the consequence or damage, if non-omission of the act prevents this occurrence." [6]

Technology, technological progress and economicindustrial development in combination with the respective damages for land, clean air and water turn out to be multi-dimensional phenomena asking for interdisciplinary and complex approaches. The multi- 
perspectivity is the result of an ongoing mutual interaction between diverse realms and actions of many corporate and individual agents. This is leading to a rather great complexity of individual, collective and corporate contributions, different areas and social background factors. The exponential structure of technological development in terms of range, energy, acceleration, interaction, feedback phenomena etc.. is a familiar insight of traditional sociology of science, technology and economic development. This insight is generally true for any multiramified and interdisciplinary interlocking of social phenomena of development.

With regard to responsibility in general, it is not only corporations and institutions in economics and industry which have to bear several sorts of responsibility (see chap. 10), but also the state and its representative decision makers. Corporate responsibility has to be connected with individual responsibilities of the respective representative decision makers. This is true also for big technology projects, particularly if they are run by the state itself. There should be not only a legal, but also a moral balance of powers in terms of checks and controls similar to the traditional distribution of power between legislature, government and jurisdiction.

The upshot of this in terms of moral responsibility might be formulated like this: The extension of individualistic responsibility is to be combined with the development of a socially proportionate co-responsibility, and with the establishment and analytic as well as institutional elaboration of social corporate responsibility (CSR) and a new sensitivity of moral conscience. Types of responsibility would have to be analyzed in a more differentiated way than hitherto (see chap. 10). Only this way we may be able to cope with the most complex structures of causal networks and the far-ranging consequences of human actions and social impacts and interactions of all respective interdisciplinary provenances to a more social orientation of responsibility and even social conscience. Much more attention should be given to that. Ethics and moral philosophy have to take notice of and tackle these new systemic challenges by utilizing the extant technically multiplied possibilities and growing impacts of interactions and system networks in our ever more complex societies. ${ }^{[11,12]}$ An applied ethics of not only collective, but also of strategic and network actions as well as their consequences would seem to be urgently needed indeed.

In the relevant publications the possibilities of a (complete) solution of the mentioned dilemmas are treated with controversy: While some offer rather individualistic propositions others suggest the complementing of institutional, structural or legal and political measures.
Not being able to comment on these more closely, we would like only to point out: A moral re-orientation of individuals is necessary, but not sufficient. ${ }^{[13]}$ In addition to a new orientation we need structural incentives, a defusing of situations which threaten to turn into a dilemma, structural changes of the framework, societal mechanisms for sanctioning and institutional legal and political measures. We need to examine a tiered system, a complete set of measures and put them into viable function if possible. This holds true in the same way for the problems in work-situations, which we have only mentioned here. The central question for avoiding social traps is how we can make sure that defection (noncooperative behaviour) will occur not at all any more (which is highly unlikely). Or not as often as hitherto or at least only to a relatively harmless degree (up to a certain threshold?).

Or, in any case, how may defection be avoided through the help of incentives? The English motto for environmental problems, "Resolution of pollution is dilution" (after 3 SAT, 10.5.1990, on a Sandoz-plant in Cork, Ireland) must and should not be the only solution! We have learned in the last decade that it is no solution at all! Also not the NIMBY-Syndrome ("Not In My Backyard")! It should be replaced by some more sophistiscated combinations of measures and corporative, collective as well as individual legal and moral responsibilities.

\section{References}

[1] Constanza R. The value of the world's ecosystems services and natural capital. Nature, 1997, 387: 253-60.

[2] Hardin G. The Tragedy of the Commons. Science,1968, 162: $1243-8$.

[3] Buchanan A. Ethics, Efficiency, and the Market. Totowa, N.J. 1985

[4] Kerber W. Sittlich handeln unter dem Zwang ökonomischer Sachzwänge. In: Hesse, H.(Ed.): Wirtschaftswissenschaft und Ethik, Berlin 1988: 241-58.

[5] Vanberg V. Markt und Organisation. Tübingen: Mohr \& Siebeck 1982.

[6] Lenk H.: Global TechnoScience and Resposibility. Berlin: LIT, 2007.

[7] Lenk H. Verantwortung für die Natur. Allgemeine Zeitschrift für Philosophie, 1983, 8: 1-18.

[8] Lenk H. Konkrete Humanität. Frankfurt/M. Suhrkamp, 1998.

[9] Lenk H, Maring M. Natur-Umwelt-Ethik. Münster: LIT, 2003.

[10] Lenk H, Ropohl G. (Eds.) Ethik und Technik. Stuttgart: Reclam 1987, 1993.

[11] Lenk H. Philosophie im technologischen Zeitalter. Stuttgart: Kohlhammer 1971, 2nd ed, 1972. 
[12] Castells M. The Information Age: Economy, Society, and Culture. Vol. 1: The Rise of the Network Society, Oxford: Blackwell - Malden MA, 1996.
[13] Lenk H. Zur Sozialphilosophie der Technik. Frankfurt/M: Suhrkamp, 1982. 